\title{
The Effect of XR in Audio Visual Medium: Consumer revolution of Virtual Platforms
} by

\author{
CARLOS EMMANUEL FERRO BELLO \\ Bachelor's degree in International Advertising, \\ University Sergio Arboleda, 2017 \\ A Major Research Paper \\ presented to Ryerson University \\ in partial fulfillment of the \\ requirements for the degree of \\ Master of Digital Media \\ in the program of Digital Media \\ Toronto, Ontario, Canada, 2019 \\ (C) Carlos Emmanuel Ferro Bello, 2019
}




\section{AUTHOR'S DECLARATION}

I hereby declare that I am the sole author of this MRP. This is a true copy of the MRP, Including any required final revisions. I authorize Ryerson University to lend this MRP to other institutions or individuals for the purpose of scholarly research I further authorize Ryerson University to reproduce this MRP by photocopying or by other means, in total or in part, at the request of other institutions or individuals for the purpose of scholarly research. I understand my MRP may be made electronically available to the public. 


\title{
Abstract
}

\section{The Effect of XR in Audio Visual Medium: Consumer revolution of Virtual Platforms}

\author{
CARLOS EMMANUEL FERRO BELLO \\ Bachelor's degree in International Advertising, \\ University Sergio Arboleda, 2017
}

This paper Investigates usage cases and consumer studies of AR/VR technologies that corroborate the positive impacts of Virtual applications in learning. Taking a look at the history of audiovisual media and the impact of screen technology in modern life, helped justify the creation of the DirectAR app which enables young Cinematography enthusiasts to learn basic concepts used in video creation. 
I want to humbly thank my parents, whose relentless pursuit of righteousness and excellence has propelled me above any other professional.

To Cami B, the best partner and friend one could ever ask for; guardian to my hopes and my motivations in life.

Big thanks to all my teachers and mentors at Ryerson University, Richard L.; Asma A. and Ahmed S.

Thank you to my peers and Mates of the MDM cohort, especially to Michael S. and Andres A.; without their support during the long nights DirectAR would have proved impossible.

Eternally grateful to all those people who have added a grain of sand to my success.

"If a door closes, and a window shuts down; when there's no way out grab an axe...BUST OPEN A WALL!" - Carlos Ferro 


\section{TABLE OF CONTENTS}

AUTHOR'S DECLARATION

ABSTRACT 3

INTRODUCTION

$\begin{array}{ll}\text { MEDIA HISTORY } & 7\end{array}$

SECOND SCREENS $\quad 8$

SOCIO-CULTURAL EFFECTS 9

XR TECHNOLOGIES

SUCCESSFUL APPLICATIONS

THE DIRECTAR PROJECT 16

REFERENCES 19 


\title{
The Effect of XR in Audio Visual Medium: Consumer revolution of Virtual Platforms
}

\author{
Carlos E.Ferro B - Carlosferro@zoho.com
}

\begin{abstract}
-
This paper Investigates usage cases and consumer studies of AR/VR technologies that corroborate the positive impacts of Virtual applications in learning. Taking a look at the history of audiovisual media and the impact of screen technology in modern life, helped justify the creation of the DirectAR app which enables young Cinematography enthusiasts to learn basic concepts used in video creation.
\end{abstract}

\section{Introduction}

In modern times artistic and Musical representations have evolved to bear a stronger sense of purpose and function in our reality, giving rise to an era dominated by media. Imagery, motion and sound began being used to represent and communicate ideas with the purpose of eliciting action. Through the use of early screens and motion animation media gained the power to shape places towards an alternate or added purpose. People could now engage with media not just as an observant, but as a participant of a live event captured on the screen. The increase of media usage for practical purposes (Toulouse-Lautrec's artistic 
poster and flyer work for example) created a demand for custom content, and eventually of many entertainment industries (like early advertising). This can be seen as the starting point of a phenomena that birthed interactive media (Ong, 1982).

\section{Media History}

Film began in the 1800 's as an innovative art form derived from many older inventions whose goal was to play with the illusion of movement and the perpetual capture of an instance of life itself. This had the result of integrating screen-based motion and interaction materially into our current environment. "Scenes" ceased to be a depiction (such is the case of still imagery) and became a live happening before our eyes. The Public could now interpret an occurrence in present instance

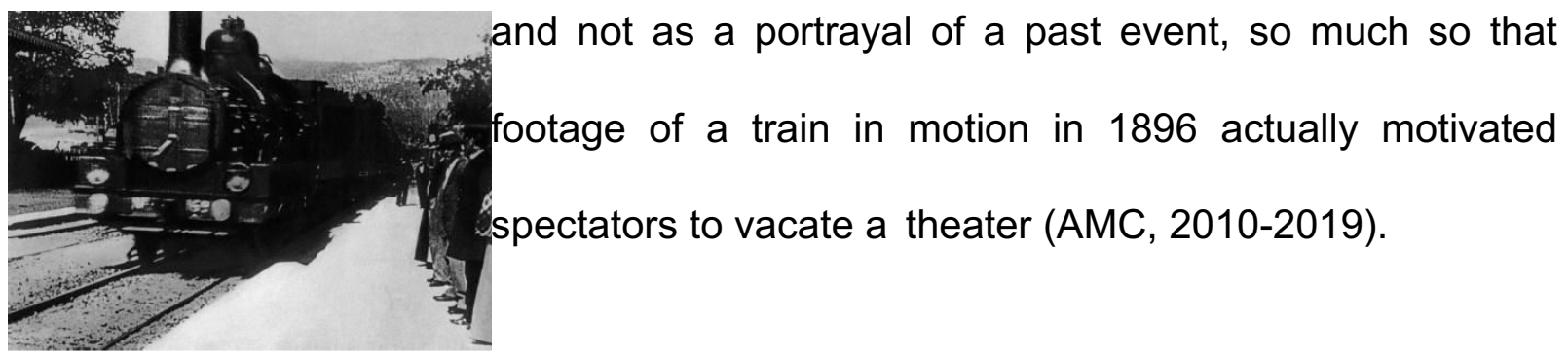

The art form in itself became so popular that it evolved into an industry, it was able to transcend its stage as a novelty to become a staple in human entertainment, and, due to a high global demand, grew to become the renowned pastime we know today. Some might even argue that going to the movies has become a ritual, and 
that film is able to communicate complex socio-political ideologies that can influence societal beliefs: films can influence foreign understanding of a country to such a degree that it can become the principal representative of an entire culture (Bollywood for India, anime for Japan and Hollywood for U.S.) (Biltereyst \& Meers, 2016).

\section{Second Screens}

In more recent years cellphone usage has become an indispensable form of interaction in daily life, and as we all know it has altered our cognitive interaction (Dos, 2014) with screens and also the way we perceive the content coming from them. While cinema benefits from the influence of a controlled physical environment, secondary screens brought with them an important sense of permanence to the audiovisual experience. But first it's important to understand what exactly a secondary screen is and which role it plays in the current media consumption environment.

In the last decade technological advancements and audience demands have made entertainment increasingly interactive, forcing audiovisual media to add a dimension which enables audiences to interact with their content in some way to maintain engagement (Mann, et al., 2015). Whether it's adding customizable viewing times, adding further information another platform or at the very least suggesting content based on a previous choice, some form of content interaction is 
occurring between viewers and their content via secondary screening (Sterling Brands; Ipsos; Google, 2012).

Secondary Screen is the term coined to refer to the content displayed on other types of devices (commonly cell phones) with the aim of integrating the viewer into the main content, thus expanding the medium into a more ubiquitous multifaceted event. (E.g. Disney's Second screen feature delivers extra content along the feature film, some can be enjoyed simultaneously while other offers extra content to further the storytelling experience) This is important for many reasons; one, because it aids marketing in reaching a larger audience; two, because it gives advertisers multimedia options for more creative promotion campaigns ultimately raising profits. However, it is key to focus on the effects the secondary screen has had on the content and its viewers themselves. Adding another layer to audiovisual media (films or TV for example) changes the way the audience interacts with the content itself. Take video platforms like YouTube or Netflix as an example we are able to display content constantly regardless of the time and setting. Right now, as this paper is being written there is a video streaming in the background! This phenomenon gives rise to the term disinterested attention, where the narrative is experienced for experience sake without further motives (Blake, 2017).

\section{Socio-cultural Effects}

Disinterested attention is one example of how technological advancements and digital media consumption lead to behavioral change. Human perception of virtual 
and digital content coupled with our new-found appreciation for media storytelling, and interactive narratives evidence a desire for real-time customizable environments. Said customizable environments have begun to exist parallel to our individual social contexts, as part of our modern reality (Vosmeer \& Schouten, 2014).

It is important to understand that media content, (viewing technologies for example) play an important role in the way we interpret our "reality" (Nišić \& Plavšić, 2014). In the words of (Jurgenson, 2012), the term augmented reality can also be understood as a perception frame-work, where digital devices intertwine the virtual with the real. Modern understanding of reality is inconceivable without some form of digital interaction of an audiovisual nature. In order to avoid confusion here forward we will differentiate perceptual "augmented realities" from AR/VR hardware technologies by coining the term "play technology", which can then be understood in the way how a digital object can alter our current reality state. "Play technology" permits the creation of rules that change our understanding of objects and places as well as the way we appropriate or inhabit them.

Where we would before attend a space designated socially for one activity (aka theater), today we stand are a point where our "play technology" allows us to redefine spaces depending on our particular need; thus, Netflix for example can now make our bus ride have the same "theatrical" experience to some degree by allowing people to consume audiovisual content on the go. When we play a movie, 
we are now redefining our "communication" device as an "entertainment" one and in the act of viewership we are also transforming our personal space into an environment for amusement. All this occurs with little to no physical change to the actual surroundings (Sicart, 2016).

Modern "play technology" devices now more than ever have the ability to blur the duality of virtual and real. Social media, for example, has given birth to the mechanics of "like and dislike" which grant or remove empowerment and validation for users in our society. Such is the power of this intangible asset it has even become a form of currency that merits payment, and it's sought after as a form of enjoyment metric. Instead of gathering amongst friends to share and value experiences now all of them are uploaded and subjected to the appreciation of everyone online: gratification on the go (Labrecque, vor dem Esche, Mathwick, Novak, \& Hofacker, 2013). People in video games are now working towards acquiring digital items, which are later sold for digital currencies or even actual dollars, eliminating the need for a brick and mortar building and also materializing actual value for what would otherwise be a non-existing digital item (Yee, 2006).

Contextual research on the existence of phenomena like partial attention and "play technology" confirm that we are in a sociocultural state that could benefit from the integration of Mixed Reality enabled devices and it is important that we also take a look at some successful case studies that justify the usage of said technologies in the Direct AR project. 


\section{XR Technologies}

As innovative as it sounds, VR and AR hardware technologies are not exactly new. Primitive versions of this medium date back to the 1960's, when dual cameras were used to simulate a first-person POV (point of view) projection of walled environments (Robertson, 2015). However, it's thanks to the ubiquitous dissemination of smart devices into mainstream life that newer immersive VR\&AR technologies are reaching the consumer public (Oculus, PlayStation VR, Nintendo Labo for example). This shift bears importance because since their genesis in the 1960's technologies have become cheaper, widely available and with a larger group of official and fan base development support. VR\&AR technologies now more than ever are able to blur the line of what we perceive as virtual and what we interpret as Real.

Kids have begun to see reality as dynamic and customizable, where media is no longer separated from reality but integrated all activities; where content now reacts to their expression or visuals become animate in real time. Factors like distance, time and even language pose less burden on how we learn, consume and understand media. Youngsters have the opportunity of becoming more expressive as they share content readily and quickly, which can (if used in a positive way) greatly improve pro-social behaviors among larger groups. They are also 
becoming more self-sufficient as they now are able to search up queries and solve doubts or even acquire skill sets from digital environments (Bailey \& Bailenson, 2017).

In a recent study performed on grade school kids that used AR technology aids for math class, researchers evaluated the affordances and limitations of the technology but also more importantly the psychological reactions of the participants and the impact on their learning process. Results showed students benefited greatly from the integration of visual interactive technologies, because the innovative nature of the device caught their interest; but more importantly because AR learning technologies enable users to re conceptualize information in new more effective ways (Wu, Wen-Yu Lee, Chang, \& Liang, 2013).

Having virtual enhancements can facilitate the learning of spatial and quantitative relationships between elements in a constant state of change. Digital media also create ample collaborative environments where classmates can cooperate in problem solving activities regardless of physical distances or location. This not only helps with social integration issues but it allows every individual equal opportunity to observe, experience and participate in the learning process, enhancing the mainstream method because it grants students accessibility to resources that are limited in physical form. In addition to enhanced connectivity there is also great customization potential which could allow users not only to individualize and adapt learning content but more importantly to integrate real life roles and situations in their learning process. Enhancing education with a practical real-life case is 
component that is always sought after. AR/VR implementations permit users to integrate role playing and dynamic multi-player roles into a multimedia experience where people are an active part of a task driven narrative that is not only performed but co-created by them (Bujak, et al., 2013). The aforementioned factors come together resulting in a space where the user can leverage physical, cognitive and contextual aspects to comprehend a specific topic of interest, while at the same time having the freedom to interact with simulations that bypass real life limitations. In one AR application students at an agronomy lecture were able to observe the growth results of certain types of flora as they alter environmental factors like soil and weather conditions in a digital overlay, regardless of the season, geographic location or weather conditions. The following practice can be viewed as purely digital or unrealistic at first, but by integrating AR technology users can then conduct fieldwork and use real photographs to compare, contrast and correct their digital environment adding another layer of relevance/accuracy to their learning tool (Bujak, et al., 2013).

\section{Successful Applications}

Examples of successful AR/VR applications are slowly becoming more plentiful, there's no better representative to this statement than Niantic's Pokémon Go (Niantic, 2016). In July 6, 2016, an AR game based on the famous Nintendo 
franchise was released, where players move around real-world locations collecting animal-like creatures. Nintendo's pocket monster formula had many previous installments but none other could measure up to Pokémon Go's success (lqbal, 2019). The augmented reality location-based components made an overwhelming difference among the general public. By adding these features, the Pokémon world was no longer a game on a screen, it was able to transcend the digital sphere and now had real dimensions that came along with it. The game incorporated geographical locations, real-time conditions and, with multiplayer mechanics, the game started affecting players socially. Players started traversing their city on a daily basis due to the games prompts; this enticed them to gather up in groups creating new social conventions, and giving rise to collaborative practices (Hilash, 2019) amongst groups of otherwise total strangers. These player groups also had gigantic social impacts on other aspects of life itself (positive and negative alike), businesses now had to adapt to intake larger crowds of consumers seeking refreshments (Uzialko, 2016), city parks had more active visitors, trespasser laws had to be enacted to prevent illegal entry (BBC News, 2018) and brands started allying with the fad in order to take advantage of the potential customers roaming around (Blue Fountain Media, 2016). Pokémon go has generated unprecedented changes in urban life and how we interact with our living spaces (Sicart, 2016).

This is, however, just the tip of the digital iceberg. Pokémon go has also been the source of deep sociological change. A wealth of articles can be read about many topics regarding Pokémon Go, covering a wide variety of scientific topics pertinent 
to humans and technological interactions. The AR app has made us question if we walk enough (Belluz, 2016), if we should legislate gaming prizes and loot boxes (Thier, 2019), what are the limits of public game play (Perry, 2016) and even if mixing the digital world with physical spaces is even legal (Lee, 2016). According to an article from Conference on Human Factors in Computing Systems, Pokémon Go has even had an effect on family dynamics and in the way, parents approach their children through technology (Takahashi, 2018). The game encourages kids to go outside and mingle, which has been taken by parents as an opportunity to tackle the issue of physical inactivity; and since the game now reaches players across various generations it has also become a bonding opportunity. The game has reportedly allowed parents to teach their younglings life lessons like sharing, fair turn taking and cooperation. Due to its simple mechanics and its ability to engage a wide range of age groups, the app bridges many gaps, young and elder alike -- Casual and hardcore gamers share a common ground. Pokémon Go started as a game app but has evolved by motivating players to re-evaluate what gaming itself means, and extending their gamified dynamics to cover important key values on the human spectrum. A game that moves you, pushes you to communicate, and allows you to cooperate effectively with others to reach a goal undoubtedly shows enormous potential for AR/VR as tool for enabling human growth (Sobel, et al., 2017).

\section{The DirectAR Project}

Undertaking the task of researching the AR/VR medium and its current impact on 
human-computing interactions, including potential functions, affordances and capabilities in design as well as current availability and usability of fairly priced common technology for the public, has led to the decision of using said digital medium in the Direct AR project. The Direct AR App aims to help fledgling film enthusiasts to acquire the necessary skills to start creating video content via cellphone devices. The app employs Augmented Reality markers that help users visualize and learn various film making concepts necessary for proficient cinematic creation.

The project seeks to create an affordable quick and ready tool to facilitate engagement with cinema filmography, and addresses the current challenges faced by starting cinematographers. Direct AR employs $3 d$ characters to functions as "actors" to illustrate camera principles and allow users to create video examples with particular lessons. Utilizing common cellphone functions like video recording we can enable currently available devices to become both the teacher and the equipment, placing the student in a "create to learn" environment where each lesson can become a unique play ground that can be shared and stored as video on their device.

Using the Unity development platform with Vuforia enables Direct AR to display animated $3 \mathrm{D}$ models by focusing the cellphone camera on commonly printed $2 \mathrm{D}$ images nicknamed X-Cards. Markers can be used in a variety of surfaces and can be printed in different formats allowing users to innovate and configure as they 
please.

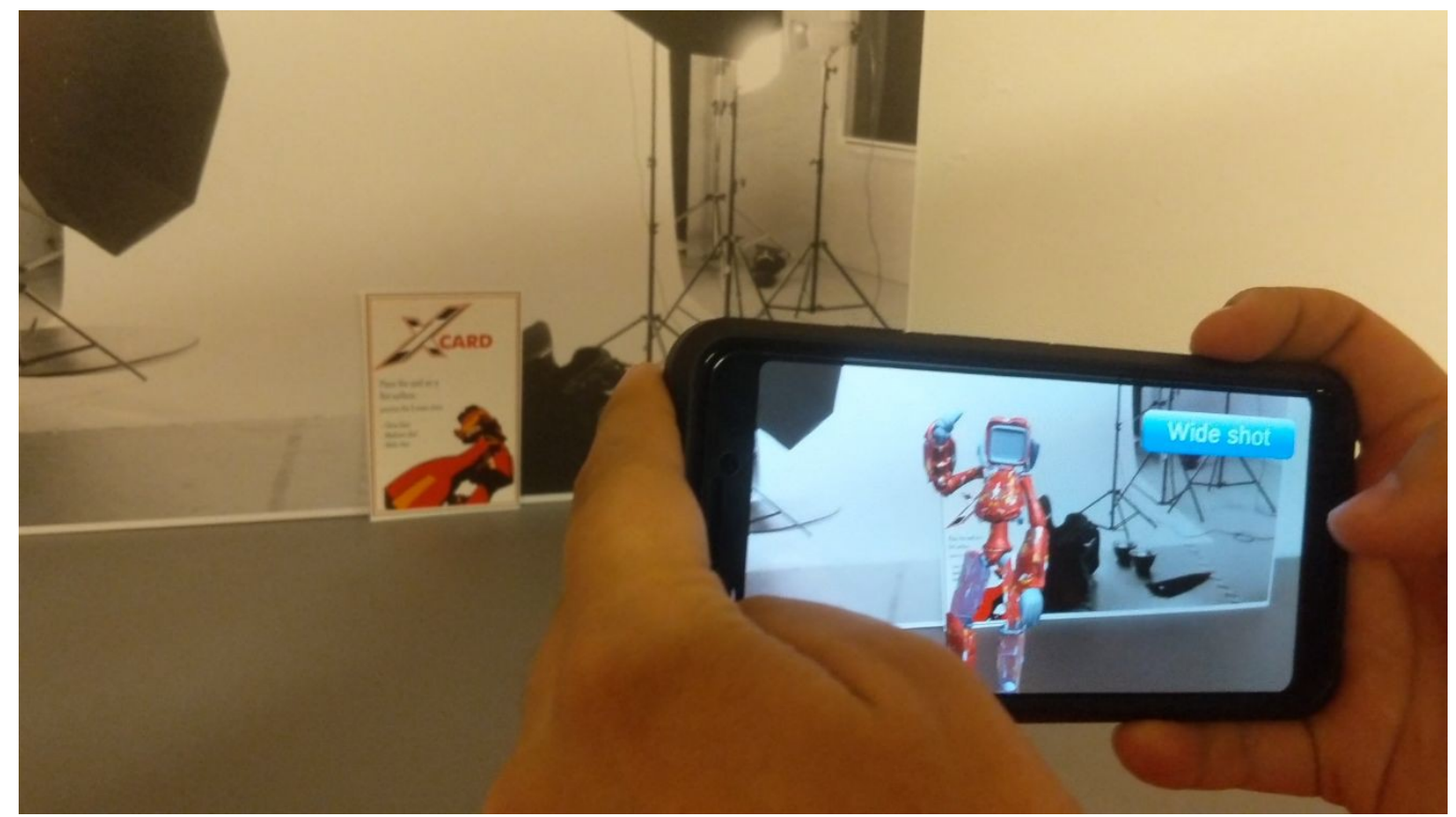

Figure 2 Direct AR app Lesson 1 "Camera Shots"

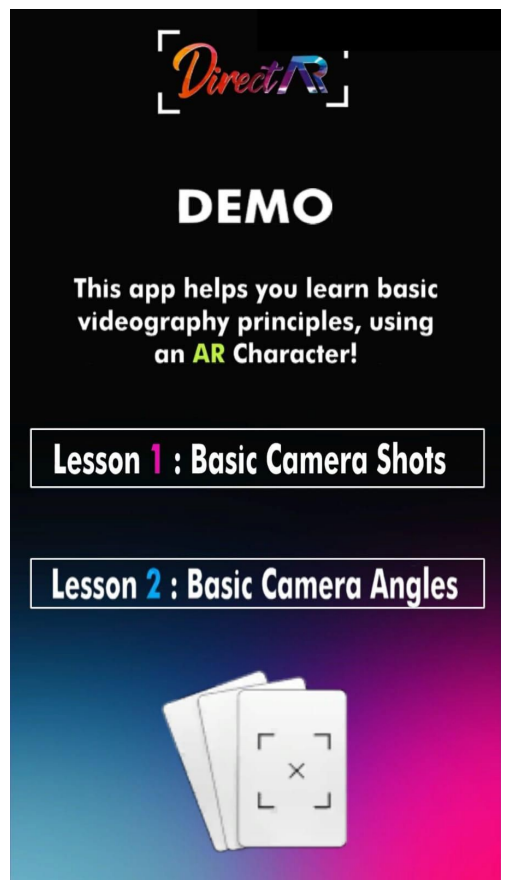

It is possible to make an educated guess that educational VR/AR technologies will become increasingly popular as functionalities become even more robust. Hardware which is now becoming widely available will build upon the preexisting conceptual frameworks aiming to merge virtual and real to an almost indistinguishable degree, especially in fields like gaming and entertainment where graphics already possess a high degree of visual realism. 
The Direct AR project aims to pioneer this event by leveraging early technologies and increasing the acceptance and validity of Mixed Reality Devices in many fields, helping train human talent and enabling a new generation of audiovisual creators.

\section{References}

AMC, E. (2010-2019). The History of Film. Retrieved from filmsite.org: https://www.filmsite.org/pre20sintro.html

Bailey, J. O., \& Bailenson, J. N. (2017). Immersive virtual reality and the developing child. Cognitive Development in Digital Contexts, 181-200.

BBC News. (2018). Pokemon Go 'trespass' legal action settled in US. BBC.

Belluz, J. (2016). Did Pokémon Go get Americans to exercise? Vox.

Biltereyst, D., \& Meers, P. (2016). New cinema history and the comparative mode: reflections on comparing historical cinema cultures. Alphavile, 13-32.

Blake, J. (2017). Second Screen interaction in the cinema: Experimenting with transmedia narratives and commercialising user participation. Participations Journal Audience \& Reception Studies, Volume 14-Issue 2.

Blue Fountain Media. (2016). Pokémarketing: How 'Pokémon GO' Is Influencing Brand Marketing.

Bujak, K. R., Radu, I., Catrambone, R., Maclntyre, B., Zheng, R., \& Golubski, G. (2013). A psychological perspective on augmented reality in the mathematicsclassroom. Computers \& Education, 536-544.

Dos, B. (2014). The Relationship Between Mobile Phone Use, Metacognitive Awareness and Academic Achievement. EUROPEAN JOURNAL OFEDUCATIONAL RESEARCH, Vol.3, No.4, 192-200.

Hilash, S. (2019). A Pokemon Go Player Saved A BC Man's Life While Playing The Game. Narcity.

Iqbal, M. (2019). Pokémon GO Revenue and Usage Statistics (2019). Business of Apps.

Jurgenson, N. (2012). When Atoms Meet Bits: Social Media, the Mobile Web and Augmented Revolution. future internet , 83-91.

Labrecque, L. I., vor dem Esche, J., Mathwick, C., Novak, T. P., \& Hofacker, C. F. (2013). Consumer Power: Evolution in the Digital Age. Journal of Interactive Marketing, 257-269.

Lee, K. (2016). Is PokemonGo Illegal? Associates Mind. 
Mann, G., Venturini, F., Murdoch, R., Mishra, B., Moorby, G., \& Carlier, B. (2015). Digital Video and the Connected Consumer. Accenture.

Niantic. (2016, July 6). Pokémon Go. San Francisco, California, United States.

Nišić, V., \& Plavšić, D. (2014). Th e role of media in the construction of social reality. Sociological discourse, year 4, number 7, 73-81.

Ong, W. J. (1982). Orality and Literacy: The Technologizing of the Word. Methuen \& co.

Perry, F. (2016). Urban gamification: can Pokémon Go transform our public spaces? . The Guardian.

Robertson, A. (2015). An 'ethereal cube' from the 1960s is the reason the Oculus Rift exists. The Verge.

Sicart, M. (2016). Reality has always been augmented: Play and the promises of Pokémon GO. Center for Computer Games Research, IT University of Copenhagen.

Sobel, K., Bhattacharya, A., Hiniker, A., Lee, J., Kientz, J. A., \& Yip, J. C. (2017). "It wasn't really about the Pokémon": Parents' Perspectives on a Location-Based Mobile Game. Conference on Human Factors in Computing Systems, 1483-1496.

Sterling Brands; Ipsos; Google. (2012). The New Multi-Screen World. U.S.: Think with Google.

Takahashi, D. (2018). Niantic games generate significant social impact in 2018. Venturebeat.

Thier, D. (2019). Pokémon GO's Eggs Have Turned Me Into A Loot Box Addict. Forbes.

Uzialko, A. C. (2016). Small Businesses Catch a Boost from Pokemon Go. Business News Daily.

Vosmeer, M., \& Schouten, B. (2014). Interactive Cinema: Engagement and Interaction. Games \& Play Research Group, CREATE-IT, 140-147.

Wu, H.-K., Wen-Yu Lee, S., Chang, H.-Y., \& Liang, J.-C. (2013). Current status, opportunities and challenges of augmented reality in education. Computers \& Education 62, 41-49.

Yee, N. (2006). The Psychology of Massively Multi-User Online Role-Playing Games: Motivations, Emotional Investment, Relationships and Problematic Usage. In N. Yee, Avatars at Work and Play (pp. 187-207). Springer, Dordrecht. 